\title{
Biosynthesis of Silver Nanoparticles by Chlorodesmis Hildebrandtii A. Gepp \& E. Gepp Including its Agricultural and Biomedical Implications
}

\section{Roy S* and Anantharaman P}

Centre of Advanced Study in Marine Biology, Faculty of Marine Sciences, Annamalai University, India

*Corresponding author: Suparna Roy; DST Woman Scientist-A; Department of Science \& Technology, Govt. of India, Marine Biology \& Oceanography, Centre of Advanced Study

\section{Research Article}

Volume 3 Issue 3

Received Date: June 02, 2018

Published Date: July 17, 2018

DOI: $10.23880 /$ nnoa- 16000144 in Marine Biology, Faculty in Marine Sciences, Annamalai University, Tamilnadu, India, Email: suparna09roy@gmail.com

\section{Abstract}

The aim of this work was to investigate the biosynthesis of Silver (Ag) Nanoparticles from aqueous extract of green seaweed Chlorodesmis hildebrandtii and its characterization. The synthesized Ag-Nanoparticles were characterized using UV-Visible Spectrophotometer, Fourier Transform Infrared Spectroscopy, Dynamic Light Scattering, Scanning Electron Microscopy and X-Ray Diffraction analysis. The biosynthesized Ag-Nanoparticles had been analysed for its inhibitory activity against some human pathogenic bacteria. The biosynthesized Ag-Nanoparticles had been tested for its potentiality to seed germination to confirm its Phyto-friendly nature and for its future use as bio-nano-fertilizer. The antibacterial activity was tested with agar disc diffusion method and the seed germination was also done according to standard protocol. The inhibitory activity of biosynthesized Silver Nanoparticles was the highest against Klebsiella pneumoniae $(1.5 \pm 0.5 \mathrm{~cm})$, followed by Escherichia coli $(0.63 \pm 0.05 \mathrm{~cm})$ and Proteus mirabilis $(0.23 \pm 0.05 \mathrm{~cm})$ than the zone of inhibition of antibiotic Chloramphenicol $(5 \mathrm{mg} / \mathrm{ml})$. The biosynthesized Ag-Nanoparticles had accelerating potentiality to seeds germination. The seed germination percentage was more in case of seeds treated with biosynthesized AgNanoparticles. The seed germination was 100 percent for both seeds of Abelmoschus esculentus and Raphanus sativus var. longinnatus. But seed germination percentage was less in case of seeds treated with normal water (60\%), seaweed extract (60\%) and seaweed liquid fertilizer (40\%).

Keywords: Seaweed; Biosynthesis; Silver Nanoparticles; Seed Germination; Antibacterial Activity

\section{Introduction}

It had been reported that chemicals originated AgNanoparticles, due to its unique physical and chemical properties especially very quick penetration with its nanosized, had adverse effect to the environment and in human health. From various industrial effluents, tonnes of free silver ions had been released in to the aqueous phase 


\section{Nanomedicine \& Nanotechnology Open Access}

which had serious adverse effect on human health such as permanent bluish-gray discolouration of the skin (argyria) and the free silver also formed some compounds which caused kidney and liver damage, skin, respiratory, eye and intestinal tract irritations and the also the changes in blood cells [1]. Some previous research showed that some seaweed had excellent activity for plant growth promotion as bio-nano-fertilizer. Such as the bio-nano-fertilizer biosynthesized by the brown seaweed Sargassum cinctum promote $80 \%$ seed germination for Abelmoschus esculentus [2], likewise Chaetomorpha antennina biosynthesized Ag-Nanoparticles promote $80 \%$ seed germination for Abelmoschus esculentus and 75\% seed germination for Raphanus sativus var. longipinnatus [3], Sargassum illicifolium biosynthesized Silver Nanoparticles germinates 60\% seeds of Abelmoschus esculentus and $60 \%$ seeds of Raphanus sativus var. longipinnatus [4] and biosynthesized Silver Nanoparticles by Amphiroa anceps germinated $80 \%$ seeds of Abelmoschus esculentus and $80-85.71 \%$ seeds of Raphanus sativus var. longipinnatus [5]. In this study, we selected green algae Chlorodesmis hildebrandtii for biosynthesis of Silver Nanoparticles and its application for potential for seed germination, trying to developed the most potent Nano-bio-fertilizer for agricultural application to promote the growth and yield.

\section{Materials and Methods}

\section{Synthesis of Silver Nanoparticles}

Seaweed extracts preparation: The fresh seaweed had been collected from Olaikuda $\left(09^{\circ} 19.700 \mathrm{~N} \&\right.$ $079^{\circ} 19.072 \mathrm{E}$ ), Rameshwaram, south-east coast of India. Seaweed was identified with standard taxonomic key of CMFRI. It was washed with in-situ sea water and distilled water thrice.

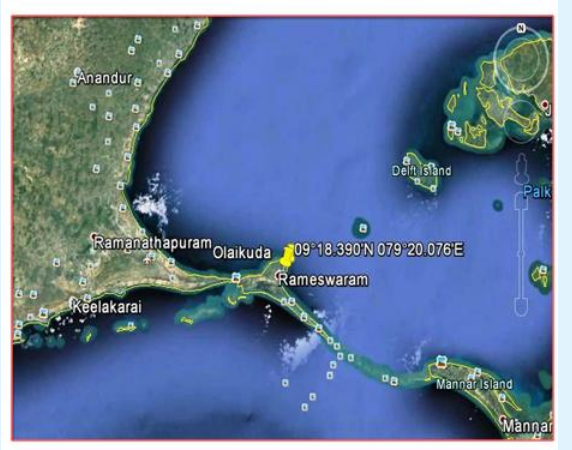

Figure 1: Map showing the sampling location.

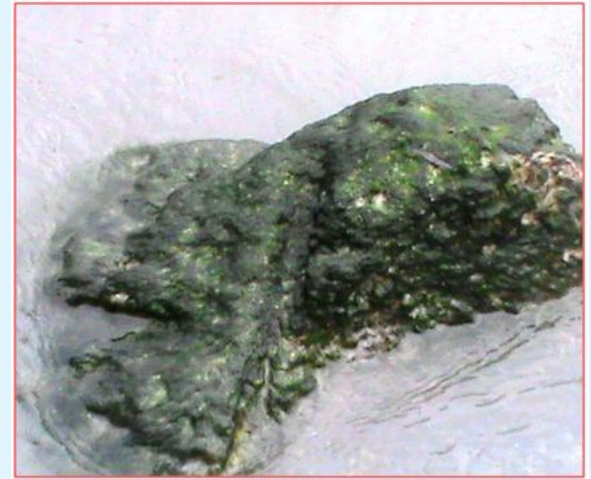

Figure 2: Showing Chlorodesmis hildebrandtii, Division-Chlorophyta, Order-Bryopsidales, ClassChlorophyceae and Family-Udoteaceae.

Then, 20 gm of seaweed was cut into very small pieces and grinded to make it powder and was dissolved into $100 \mathrm{ml}$ of distilled water and boiled for 10 minutes. The crude extract of seaweed was filtered with Whatman No. 1 filter paper and repeatedly filtered with thin layer of cotton to get clear seaweed extract. This crude seaweed extract was stored in $4^{\circ} \mathrm{C}$ for further use (Figures $1 \& 2$ ).

Synthesis of Ag-Nanoparticles: The aqueous $1 \mathrm{mM}$ $\mathrm{AgNO}_{3}$ solution was prepared with Silver nitrate. For typical synthesis of Silver Nanoparticles, $10 \mathrm{ml}$ of the aqueous extract of seaweed was added to the $90 \mathrm{ml}$ aqueous solution of Silver Nitrate in $250 \mathrm{ml}$ conical flask and kept in room temperature for 72 hours within mechanical shaker at $120 \mathrm{rmp}$. The colour change of solution indicated the formation of Silver Nanoparticles.

\section{Characterization of Ag-Nanoparticles}

UV-Vis Spectrophotometer: After 72 hours synthesis of particles, for characterization, the solution was scanned (300-700nm) with UV-Vis Spectrophotometer (UV-2600 SHIMADZU) and distilled water was used as blank.

Fourier Transform Infrared (FT-IR) Spectroscopy: After synthesis of particles, the solution had been centrifuged at $5000 \mathrm{rmp}$ for 30 minutes to precipitate the pellet of particles at the bottom, then the supernatant were removed and pellet collect and dried at room temperature to make dry powder. The chemical composition of the seaweed was characterized by Perkin Elmer FTIR model 2000. The $1 \mathrm{mg}$ of dry powder of particles was mixed with $\mathrm{KBr}$ and made it pellet and used for FT-IR analysis at $\mathrm{KBr}$ mode. 


\section{Nanomedicine \& Nanotechnology Open Access}

Scanning Electron Microscopy: The dry powder of sample was analysed using JEOL JSM-5610LV Scanning Electron Microscope. Thin films of the sample was prepared on a gold coated copper grid by just spraying a very small amount of the powder sample on the grid; and then the film on the SEM grid was allowed for observation.

X-Ray Diffraction Measurements: The dried biosynthesized Silver Nanoparticles were sprayed on measurement cuvette and measured under BRUKER D8 ADVANCE POWDER X-ray diffractometer. The samples were analysed from 20 to $80^{\circ}$ theta $(\theta)$ range and the operating voltage was $20 \mathrm{KV}$.

Test on seed germination: The seeds of Abelmoschus esculentus (Family-Malvaceae) and Raphanus sativus var. longinnatus (Family - Brassicaceae) were dipped within 5\% Sodium hypochlorite solution for 15 minutes to ensure seed surface sterility and soaked with Silver Nanoparticles solution for overnight and seeds were also soaked for overnight with normal tape water as control. Then, each piece of filter paper was wetted with $5 \mathrm{ml}$ Silver nanoparticles solution and placed in the Petri plates. The treated seeds were kept on filter paper within Petri plates. Then Petri plates were covered and incubated at room temperature. After 12 hours germination halted and the germination percentage, mean germination time, germination index, relative root elongation, relative seed germination and germination rate were estimated. Germination parameters were calculated using mentioned equations in some literatures [6-9].

Antimicrobial activity: Antibacterial activity of synthesized Ag-Nanoparticles using aqueous extract of Halimeda gracilis was assayed by agar disc diffusion method against six human pathogenic bacteria such as Klebshilla pneumonium, Pseudomonas aeruginosa, Staphylococcus aureus, Escherichia coli, Enterococcus faecalis and Proteus mirabilis which were collected from Department of Medical Microbiology, Raja Muthiah Medical College, Annamalai University. The bacterial cultures were freshly prepared in nutrient broth which was sub-cultured from pure culture. After 24 hours of culture, each bacterial culture was inoculated into the agar plates and kept for 24 hours. The market available Chloramphenicol antibiotic was used as positive control. The $500 \mathrm{mg}$ powder Chloramphenicol was dissolved in $100 \mathrm{ml}$ autoclaved distilled water to made concentration of $5 \mathrm{mg} / \mathrm{ml}$. The $1 \mathrm{mM} \mathrm{AgNO}_{3}$ solution was used as negative control. The $20 \mu \mathrm{l}$ of seaweed synthesized silver nanoparticles solution, solution of negative control and positive control was given to sterile paper discs and the discs were placed on bacterial plates. After 24 hours of incubation, the zones of inhibition were measured in triplicates from three different plates.

\section{Statistical Analysis}

Mean and standard deviations were derived from measurements on three replicates for each treatment and the related controls for biochemical composition and total phenol.

\section{Results and Discussions}

\section{Synthesis of Silver Nanoparticles}

It is well known that Ag-NPs exhibit reddish-brown in water [10]. The mixing of seaweed aqueous solution with Silver Nitrate $(1 \mathrm{mM})$ produced dark brownish colour in compare to control Silver nitrate solution and the aqueous seaweed solution which suggested the formation of Ag-NPs by reduction of the aqueous Ag+ (Figure 2). Due to the surface Plasmon vibrations among the produced silver nanoparticles, the color change occurred [11] (Figure 3).

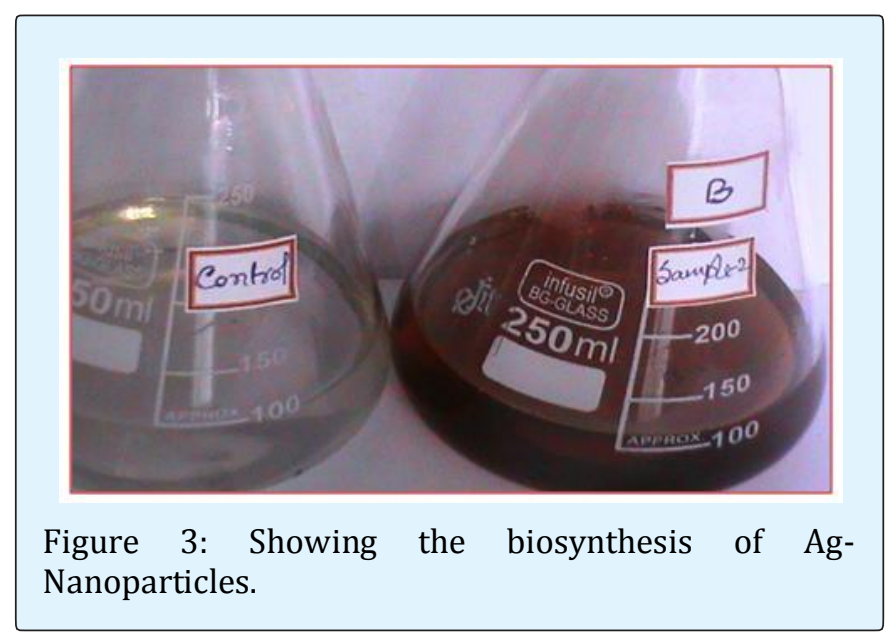

\section{Characterization of Synthesized Nanoparticles}

The broad stretch of peak at $448.5 \mathrm{~nm}$ (OD-0.856) indicated the synthesis of Silver Nanoparticles (Figure 4).

The FT-IR analysis was done for normal seaweed distilled water extract and the biosynthesized Silver Nanoparticles to know the present functional groups. The stretches and bends at $3410.47 \mathrm{~cm}^{-1}$ indicated the presence of amine and amino groups, the broad and flat 


\section{Nanomedicine \& Nanotechnology Open Access}

stretch at $2735.08 \mathrm{~cm}^{-1}$ was produced due to presence of acid $(\mathrm{O}-\mathrm{H})$ and aldehydes $(\mathrm{C}=\mathrm{O})$, including the presence of alkenes group for the peak produce at $993.42 \mathrm{~cm}^{-1}$ in IR spectra. But the IR spectra of the biosynthesized Silver Nanoparticles showed several peaks and bends at several wavelengths which indicated the presence of more functional groups than the seaweed aqueous extract.

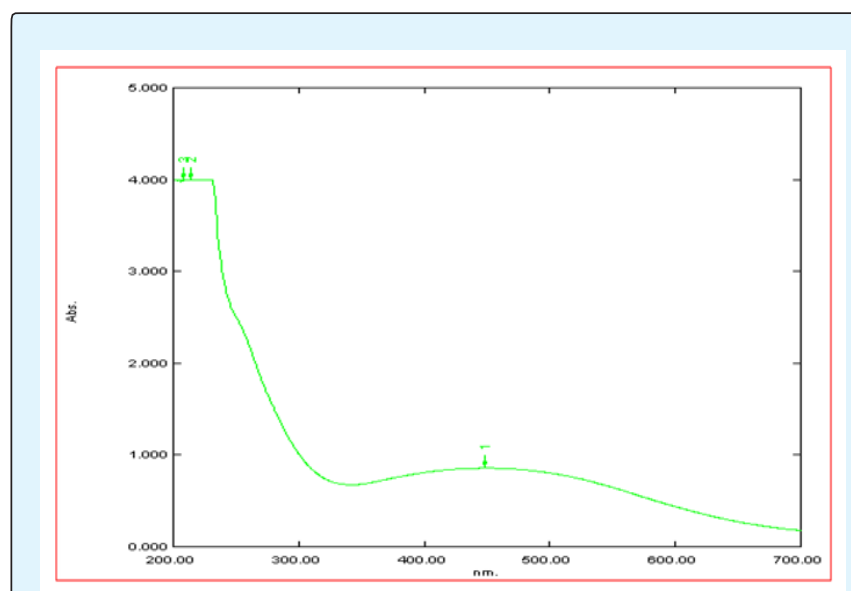

Figure 4: Showing UV-Vis Spectra of synthesized AgNanoparticles.

The broad stretch at $3448.15 \mathrm{~cm}^{-1}$ revealed the presence of amine $(\mathrm{N}-\mathrm{H})$ or alcohol $(\mathrm{O}-\mathrm{H})$ group, bend at $2920.20 \mathrm{~cm}^{-1}$, which for the presence of alkanes (C-H), the stretch at $2849.30 \mathrm{~cm}^{-1}$ produced due for the presence of aldehydes group, $1631.74 \mathrm{~cm}^{-1}$ peaks for the presence of alkenes $(\mathrm{C}=\mathrm{C})$ and amide $(\mathrm{N}-\mathrm{H})$, especially the broad peak at $1382.55 \mathrm{~cm}^{-1}$ produced for nitro group (N-O), 1019.92 $\mathrm{cm}^{-1}$ indicated for the presence of ester group or may be for alkyl halide. The comparative results showed that biosynthesized Silver Nanoparticles had nitro group but the same peak was not present in IR spectra of the aqueous extract of the seaweed (Figures $5 \& 6$ ). The scanning electron microscopic images showed the presence of high density, spherical shaped and well distributed Silver Nanoparticles biosynthesized from Chlorodesmis hildebrandtii aqueous extract and the size of biosynthesized Silver Nanoparticles was ranged from 10 $\mathrm{nm}$ to $100 \mathrm{~nm}$ (Figure 7).

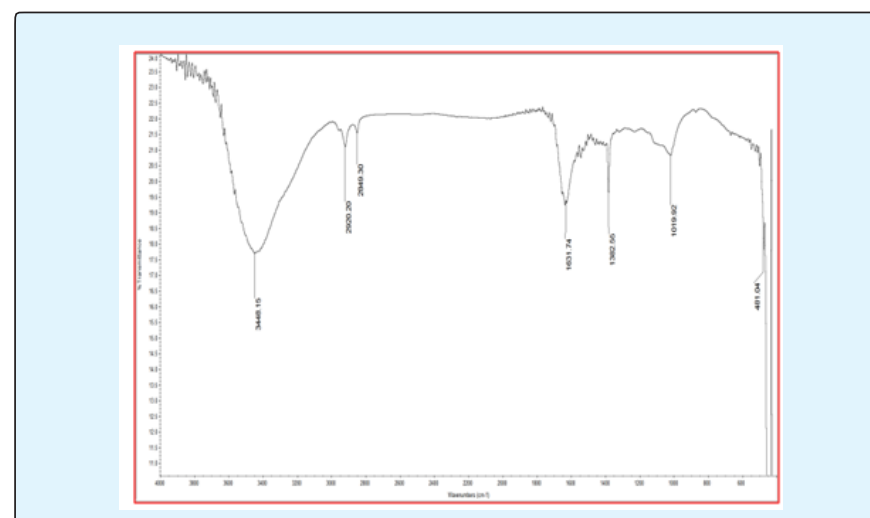

Figure 5: Showing FT-IR Spectra of Silver Nanoparticles.

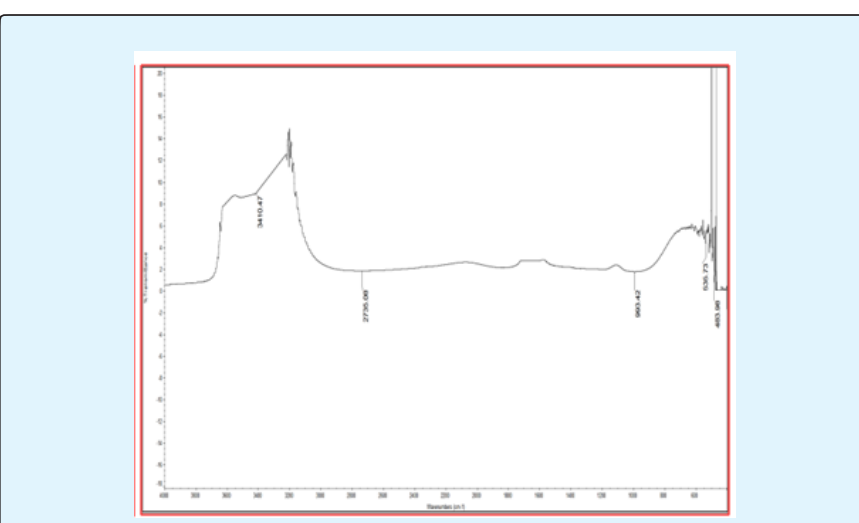

Figure 6: Showing FT-IR Spectra of aqueous extract.

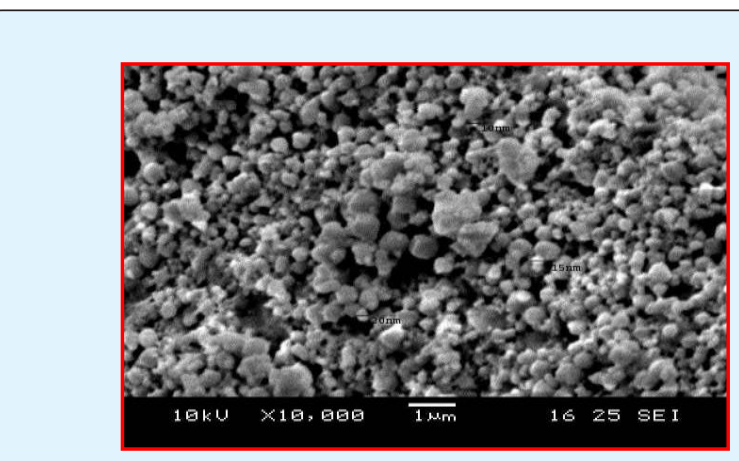

Figure 7: Showing SEM images of biosynthesized Silver Nanoparticles. 


\section{Nanomedicine \& Nanotechnology Open Access}

\section{Dynamic Light Scattering Study}

The Z-average size distribution of Ag-Nanoparticles was found $256.2 \mathrm{~d} . \mathrm{nm}$ and particles were well distributed in the water solution (Figure 8). The zeta potential value of $\mathrm{Ag}$ nanoparticles, - $28.6 \mathrm{mV}$, indicated the high stability of Ag-nanoparticles (Figure 9), it may be due to the high repulsive and attractive force exist between nanoparticles. Similar study was found in Gracilaria corticata, zeta potential was $-26.2 \mathrm{mV}$ reported by Kumar et al. (2013) [12].

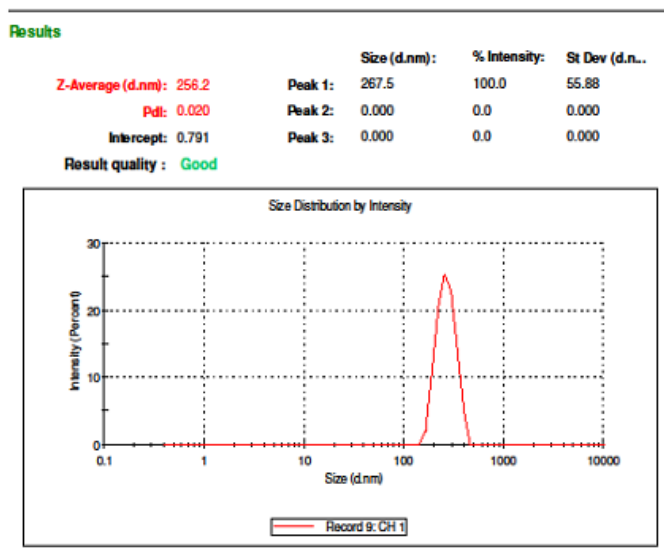

Figure 8: Showing size distribution of biosynthesized Silver Nanoparticles.

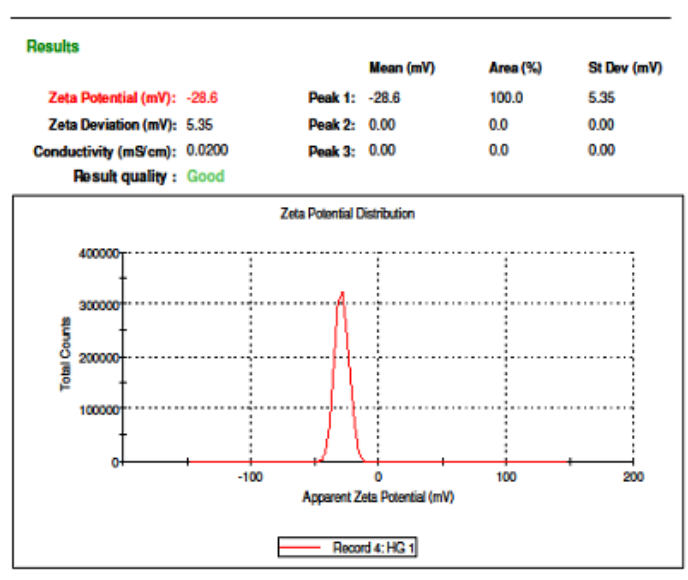

Figure 9: Showing Zeta potential of biosynthesized Silver Nanoparticles.

\section{X-ray Diffraction Measurement}

The specific nature of biosynthesized Silver Nanoparticles was analysed by XRD spectrum. The peaks produced in X-ray diffraction spectrum demonstrated the formation of spherical biosynthesized Silver Nanoparticles as the peaks have broader base and the narrower apex which indicated the presence of reduced crystal size Silver Nanoparticles. The observed peaks were found at $2 \theta$ values at $27.50,32.25^{\circ}, 47.25^{\circ}$ and 51.25. The equation used for analysis of the grain size as: $\beta=\pi / 180 \times$ width ( $\mathrm{x}$ ); $\mathrm{D}=\mathrm{k} \lambda / \beta \cos \theta$ (nm), $X=0.21246,2 \theta$ $=32.50^{\circ}$. The grain size (D) was $31.52 \mathrm{~nm}$ (Figure 9a).

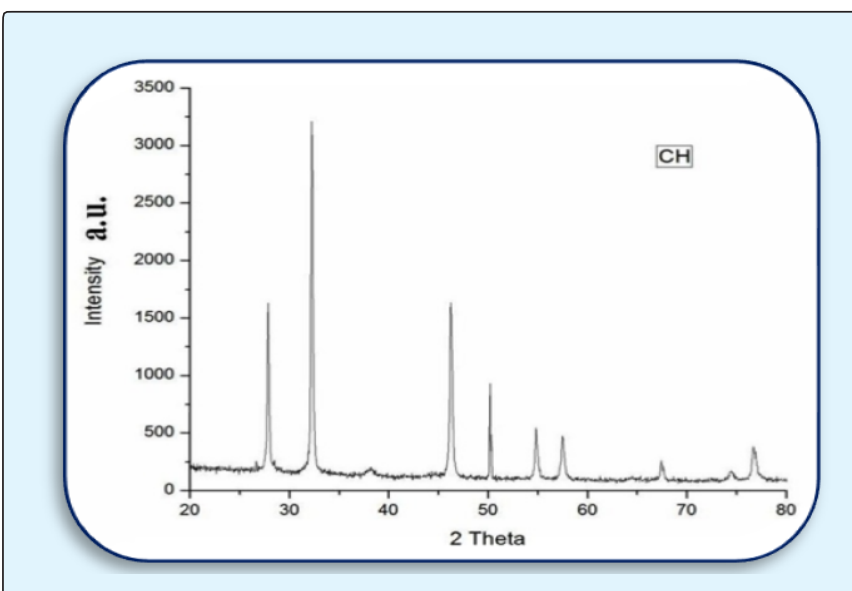

Figure 9a: Showing the XRD graph of biosynthesized Silver Nanoparticles.

\section{Potential for Seed Germination}

Experiment on seeds of Abelmoschus esculentus: The relative seed germination of seeds of Abelmoschus was maximum at 24 hours and 48 hours with the highest relative seed germination (250) and the germination index (857.14) and the next highest germination index was 845.07 at 96 hours with the highest relative root elongation (Figure 10a). The germination percentage was the highest (100 percent) after 24, 48 and 96 hours of treatment with biosynthesized Silver Nanoparticles in comparison to seeds germination with the normal water treatment as blank (Figure 10b). The mean germination rate was the maximum at 24 hours $(0.17$, followed by 48 (0.096) hours of treatment with biosynthesized Silver Nanoparticles in comparison to the rate of seed germination with normal water treatment (Figure 10d). The mean germination time of seeds of Abelmoschus was less at 24 hours (1.2), it indicates faster seed germination with treatment of biosynthesized Silver Nanoparticles, followed by 48 hours (1.4) and 96 hours (1.8) (Figure 10c). 


\section{Nanomedicine \& Nanotechnology Open Access}

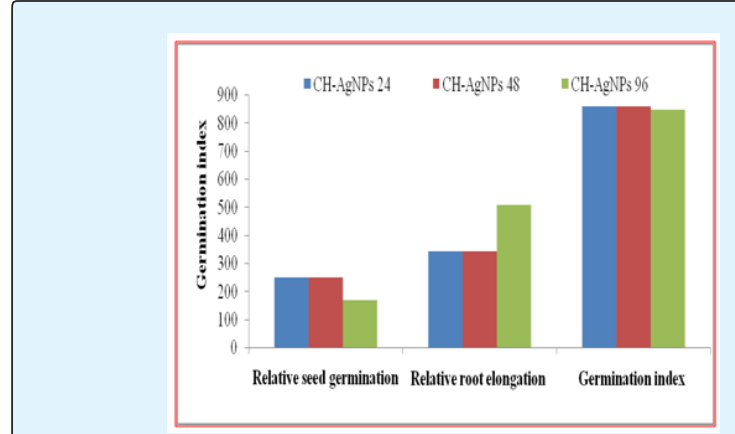

Figure 10a: Showing seed germination index.

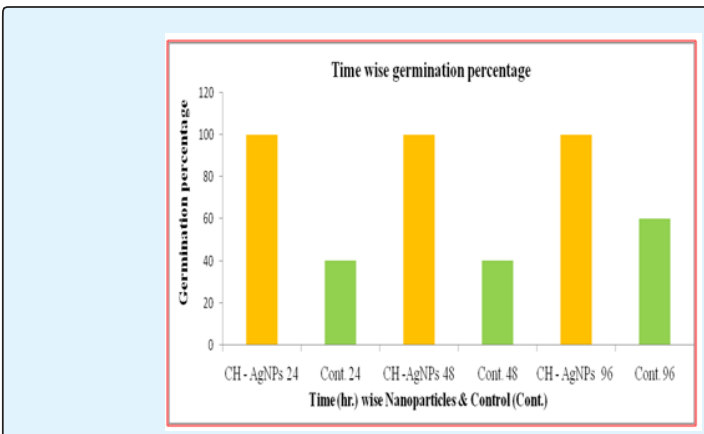

Figure 10b: Showing seed germination percentage.

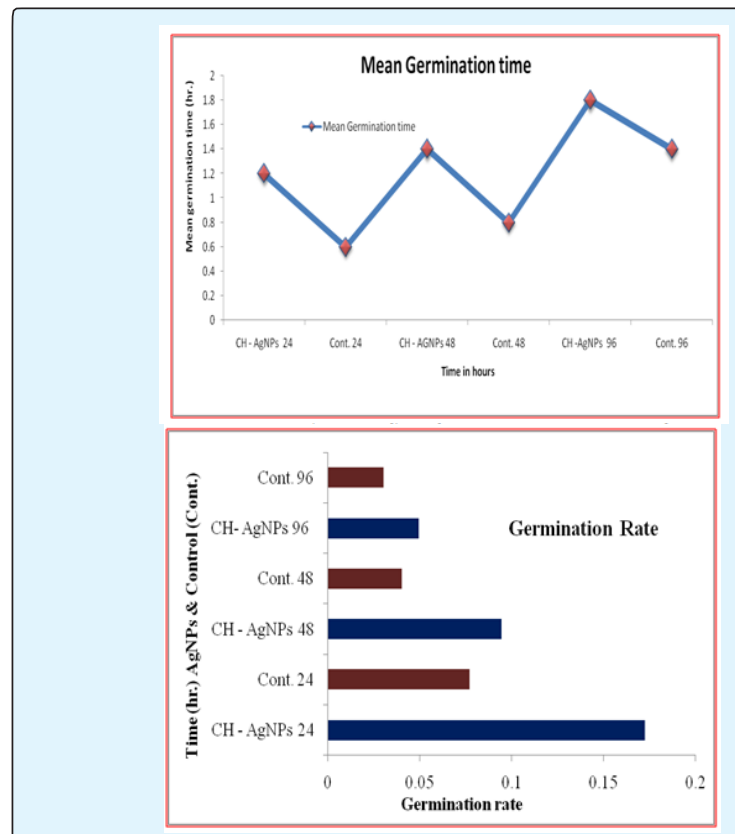

Figures 10c, 10d: Showing mean seed germination time and rate. $\mathrm{CH}-$ (Chlorodesmis hildebrandtii) and Cont. - Control (Normal water treatment).
Experiment on seeds of Raphanus sativus var. longipinnatus: The seed germination index of Raphanus with treatment of biosynthesized Silver Nanoparticles, was maximum at 24 hours (93.33) and the relative seed germination was maximum at 48 hours (200) (Figure 11c). The seed germination percentage was higher for the seeds treated with Silver Nanoparticles for 24 hours, 48 hours and 96 hours in comparison to normal water treatment. The seed germination was $80 \%$ at 24 hours of treatment with biosynthesized Silver Nanoparticles and $100 \%$ at 96 hours and 48 hours (Figure 11d). The germination rate was maximum at 24 hours $(0.14)$ of treatment of seeds with biosynthesized Silver Nanoparticles, followed by 48 hours of treatment (0.11) and 96 hours in compare to seed germination rate of seeds treated with normal water (Figure 11e). The mean germination time was less at 24 hours of treatment, in compare to 48 hours and 96 hours of treatment with biosynthesized Silver Nanoparticles (Figure 11f).
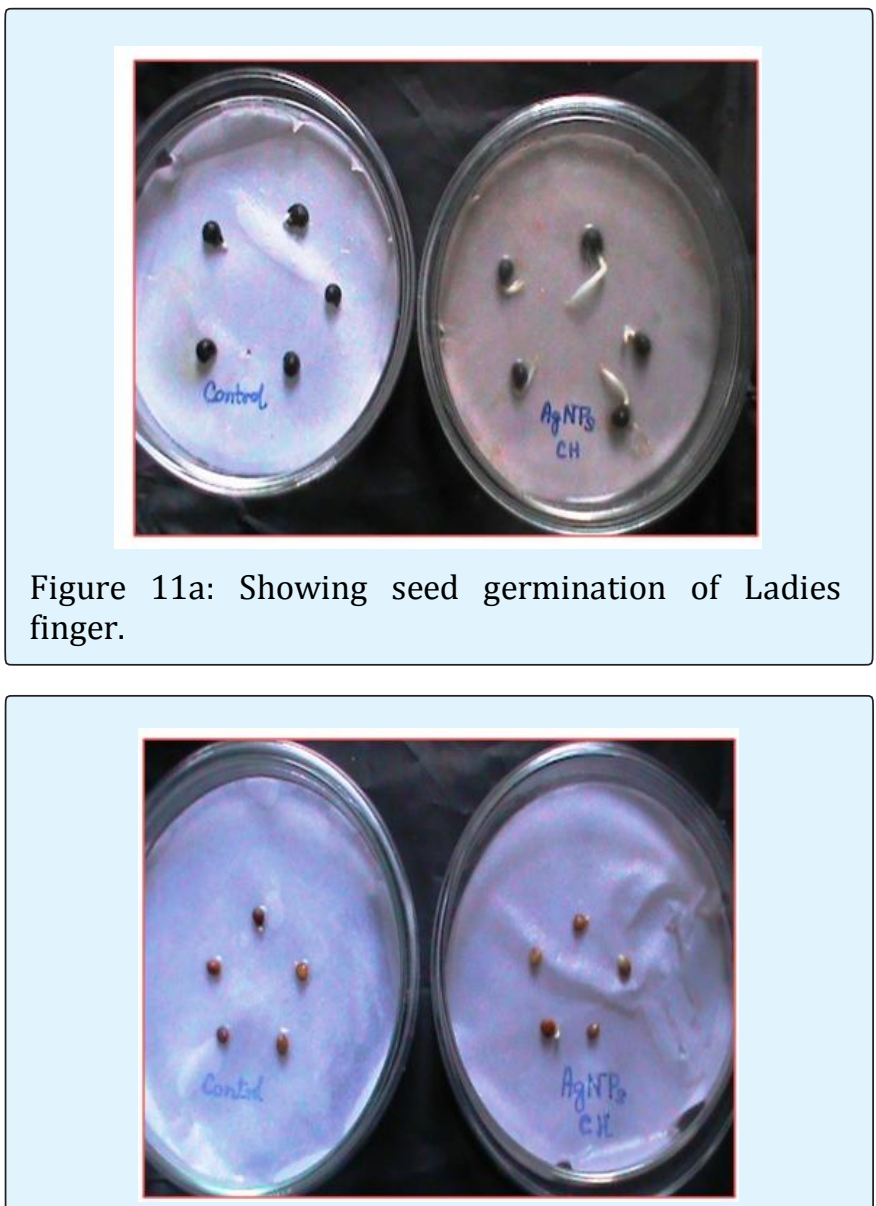

Figure 11b: Showing seed germination of Radish. 


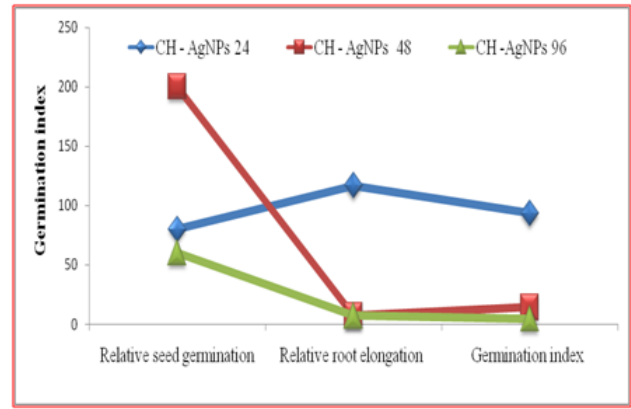

Figure 11c: Showing seed germination index.

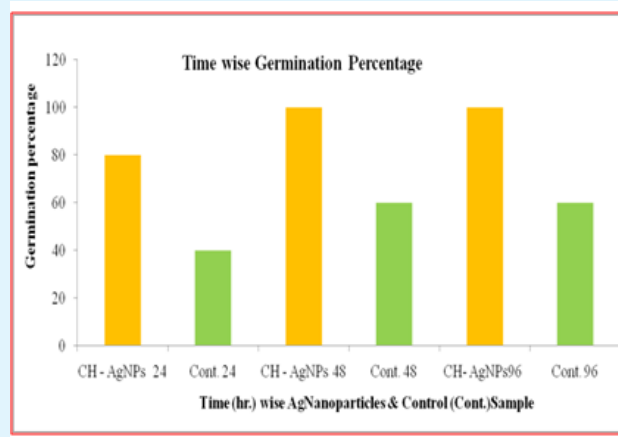

Figure 11d: Showing seed germination percentage.

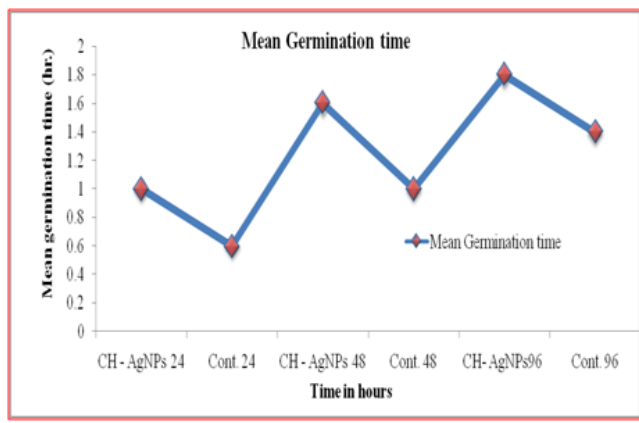

Figure 11e: Showing mean seed germination time.

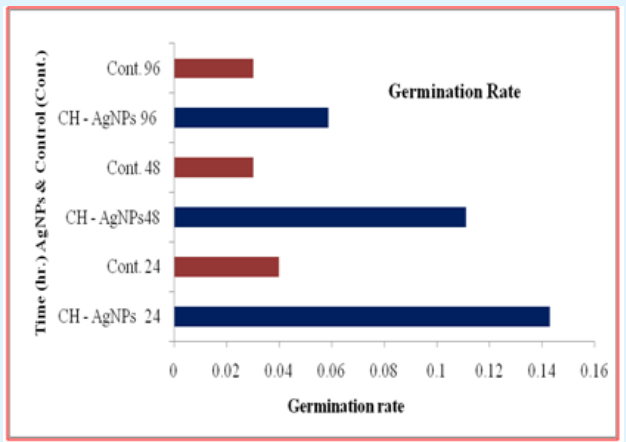

Figure 11f: Showing seed germination rate.
Experiment on seeds with normal water, seaweed extract and seaweed liquid fertilizer: For the comparative evaluation of seed germination, seeds were also treated with seaweed extract and seaweed liquid extract along with the normal water as blank and the biosynthesized Silver Nanoparticles. In case of ladies finger, no seed germination occurred with the treatment of seaweed extract and seaweed liquid fertilizer and $1 \mathrm{mM}$ $\mathrm{AgNO}_{3}$, but the seeds treated with normal water had $60 \%$ germination and seeds treated with biosynthesized Silver Nanoparticles had $100 \%$ germination. In case of radish seeds, the highest seed germination occurred for the seeds treated with biosynthesized Silver Nanoparticles which was $100 \%$, followed by seeds treated with normal water and seaweed extract, the germination was $60 \%$ but seed germination was $40 \%$ in case of seeds treated with seaweed liquid fertilizer and no seed germination occurred in case seeds treated with $1 \mathrm{mM} \mathrm{AgNO}$. From, this comparative study, it was concluded that the biosynthesized Silver Nanoparticles had best promoting and boosting effect on seed germination of both species rather than normal water or seaweed extract or seaweed liquid fertilizer (Figures 12a \& 12b).

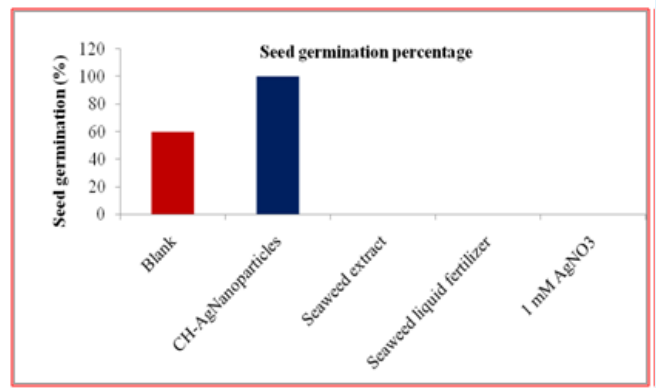

Figure 12a: Showing Ladies finger seed germination percentage

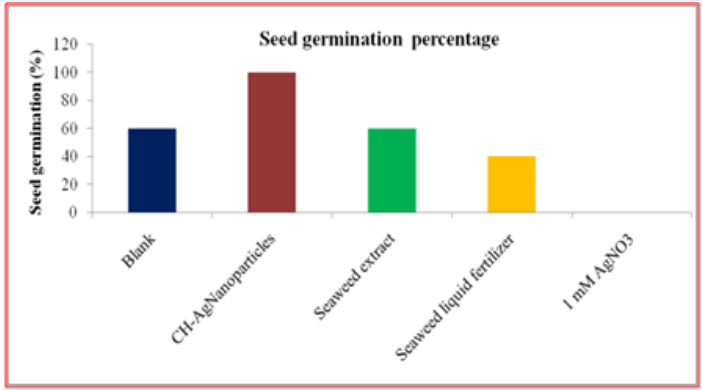

Figure 12b: Showing Radish seed germination percentage. 


\section{Nanomedicine \& Nanotechnology Open Access}

\section{Antibacterial Activity}

The antibacterial activity of biosynthesized Silver Nanoparticles was assayed for six human pathogenic bacteria such as Klebsiella pneumoniae, Pseudomonas aeruginosa, Staphylococcus aureus, Escherichia coli, Enterococcus faecalis, and Proteus mirabilis, the different strain of which had been reported for multidrug resistant properties. The highest inhibitory zone was found against Klebsiella pneumoniae, the zone of inhibition was $1.5 \pm 0.5 \mathrm{~cm}$, the next highest zone of inhibition produced against Escherichia coli $(0.63 \pm 0.05 \mathrm{~cm})$, followed by
Proteus mirabilis $(0.23 \pm 0.05 \mathrm{~cm})$, in comparison to the zone of inhibition of antibiotic Chloramphenicol $(5 \mathrm{mg} / \mathrm{ml})$ and $\mathrm{AgNO}_{3}(1 \mathrm{mM})$ as negative control. The inhibitory activity of $\mathrm{AgNO}_{3}(1 \mathrm{mM})$ was less for all six pathogens in comparing to seaweed synthesized Silver Nanoparticles and the antibiotics. But the inhibitory effect of seaweed synthesized Silver Nanoparticles was very less for Pseudomonas aeruginosa, Staphylococcus aureus and Enterococcus faecalis in comparing to antibiotic Chloramphenicol $(5 \mathrm{mg} / \mathrm{ml})$ and the negative control $\mathrm{AgNO}_{3}(1 \mathrm{mM})$ (Figure 13).

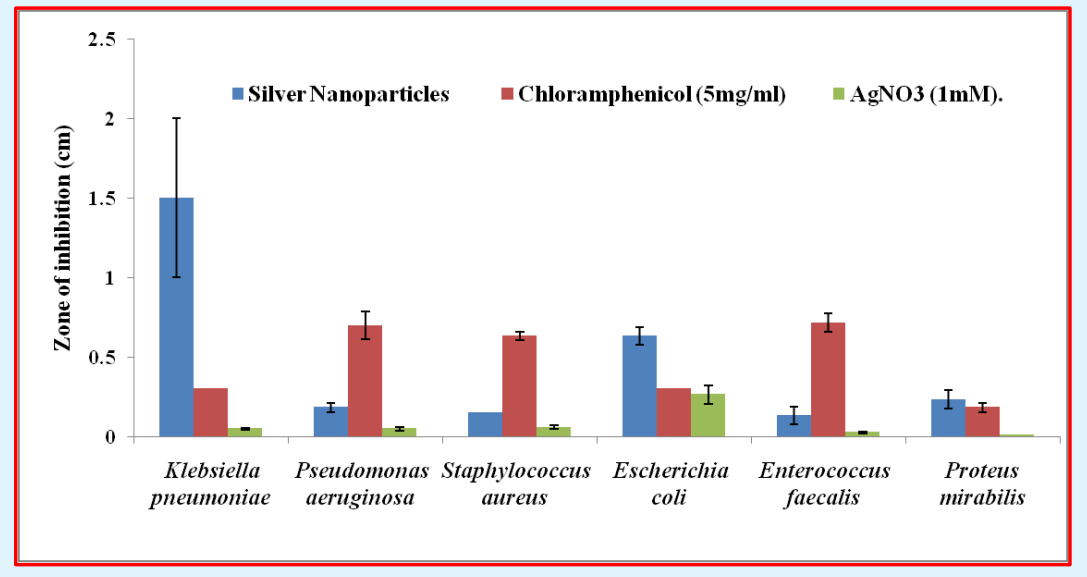

Figure 13: Showing the antibacterial activity of biosynthesized Silver Nanoparticles.

\section{Conclusions}

Current study attempted the biosynthesis of Silver Nanoparticles by using five seaweeds such Chlorodesmis hildebrandtii. The biosynthesized Silver Nanoparticles from Chlorodesmis hildebrandtii showed $100 \%$ seed germination for both ladies finger and radish seeds. The time dependent treatment of seeds by biosynthesized Silver Nanoparticles showed that increased of duration of treatment of seeds with biosynthesized Silver Nanoparticles had promoting effect of seed germination. The seeds germination ranged from $20-60 \%$ for both the seeds treated with normal water as control. For seaweed extract and seaweeds liquid bio fertilizer treatment, the seeds germination ranged from $20-60 \%$ for both seeds. It can be concluded that biosynthesized Silver Nanoparticles from Chlorodesmis hildebrandtii had the best positive promoting effect on seed germination of both studied seeds. So, after further investigation of the effect of this biosynthesized Silver Nanoparticles on fruiting and whole life cycle of these two vegetables plants, it will be confirmed to use the biosynthesized Silver Nanoparticles as bio-nano-fertilizer. There are a few of literatures available regarding the application of biosynthesized Silver Nanoparticles as bio-nano-fertilizer. So, this current study will be initiatory approach to develop the nano-biofertilizer form biosynthesized Silver Nanoparticles from seaweed. This work is first approach on the study of the potentiality of these particular seaweed synthesized Silver Nanoparticles for seed germination and seedling growth. The bio-nano-fertilizer will be applicable to the mass scale field cultivation of crop and vegetables production after its trial with whole life cycle of the vegetable plants or crop plants.

\section{Acknowledgements}

The authors are thankful to the Head of the Department and staff members of Department of Microbiology, Rajah Muthiah Medical College, Annamalai 


\section{Nanomedicine \& Nanotechnology Open Access}

University for providing the bacterial culture. Authors are thankful for the kind help of Dr. P. Kumar, Assistant Professor, Department of Animal Health and Management 6th Floor, Science Campus, Alagappa University, Karaikudi for Dynamic Light Scattering (DLS) analysis. The authors are thankful to the Head of the Department, and Dr. B. Shanthi and Dr. K. Siva Kumar at the Centralised Instrumentation and Service laboratory (CISL) at Department of Physics, Annamalai University for providing the Scanning Electron Microscopy facility and Professor. Dr. S. Kabilan, Dean, Faculty of Science, at Department of Physics for providing the FT-IR facility. Our sincere thank to the Dean, Faculty of Marine Sciences, and Director, Centre of Advanced Study in Marine Biology, Faculty of Marine Sciences, Annamalai University for their support to complete the successfully. Authors are also thankful to higher authorities of Annamalai University.

Conflict of Interest: There are no conflicts of interest to be declared.

Funding: Authors are thankful to Department of Science \& Technology, Govt. of India for their financial support.

\section{References}

1. Panyala NR, Pena-Mendez EM, Havel J (2008) Silver or Silver Nanoparticles: a hazardous threat to the environment and human health. J Appl Biomed 6(3): 117-129.

2. Roy S, Anantharaman P (2017) Green Synthesis of Silver Nanoparticles by Sargassum cinctum J. Agardh and their Potential for Seed Germination. International Journal of Trend in Scientific Research and Development 1(5): 1216-1225.

3. Roy S, Anantharaman P (2017) Biosynthesis of Silver Nanoparticles by Chaetomorpha antennina (Bory de Saint-Vincent) Kutzing with its antibacterial activity and ecological implication. Journal of Nanomedicine and Nanotechnology 8(5): 2-9.
4. Roy S, Anantharaman P (2018) Biosynthesis of Silver Nanoparticles by Amphiroa anceps (Lamarck) Decaisne and its Biomedical and Ecological Implications. Journal of Nanomedicine and Nanotechnology 9(2): 2-5.

5. Roy S, Anantharaman P (2018) Biosynthesis of Silver Nanoparticles by Sargassum Ilicifolium (Turner) C. Agardh with their antimicrobial activity and potential for seed germination. Journal of Applied Physics \& Nanotechnology 1(1): 2-9.

6. Singaravelu G, Arockiyamari J, Ganesh Kumar V, Govindaraju K (2007) A novel extracellular biosynthesis of monodisperse gold nanoparticles using marine algae, Sargassum wightii Greville. Colloids Surf B Biointerfaces 57(1): 97-101.

7. Taga MS, Miller EE, Pratt DE (1984) Chia seeds as a source of natural lipids antioxidants. J Am Oil Chem Soc 61(5): 928-993.

8. Barrena R, Casals E, Colon J, Font X, Sanchez A, et al. (2009) Evaluation of the eco-toxicity of model Nanoparticles. Chemosphere 75(7): 850-857.

9. Thakkar KN, Mhatre SS, Parikh RY (2010) Biological synthesis of metallic nanoparticles. Nanomedicine 6(2): 257-262.

10. Damle C, Kumar A, Sastry M (2002) Synthesis of $\mathrm{Ag} / \mathrm{Pd}$ nanoparticles and their low-temperature alloying within thermally evaporated fatty acid films. J Phys Chem B 106: 297-302.

11. Mulvaney P (1996) Surface Plasmon Spectroscopy of Nanosized Metal Particles. Langmuir 12(3): 788-800.

12. Kumar P, Selvi SS, Govindaraju M (2013) Seaweedmediated biosynthesis of silver nanoparticles using Gracilaria corticata for its antifungal activity against Candida spp. Appl Nanosci 3(6): 495-500. 